\title{
Management and prevention of chronic obstructive pulmonary disease exacerbations: a state of the art review John R Hurst* and Jadwiga A Wedzicha
}

\author{
Address: Academic Unit of Respiratory Medicine, Royal Free Campus, UCL Medical School, London, UK \\ Email: John R Hurst* - j.hurst@medsch.ucl.ac.uk; Jadwiga A Wedzicha - j.a.wedzicha@medsch.ucl.ac.uk \\ * Corresponding author
}

Published: 7 August 2009

BMC Medicine 2009, 7:40 doi:10.1186/174I-7015-7-40
Received: 9 July 2009

Accepted: 7 August 2009

This article is available from: http://www.biomedcentral.com/I74|-70I5/7/40

(C) 2009 Hurst and Wedzicha; licensee BioMed Central Ltd.

This is an Open Access article distributed under the terms of the Creative Commons Attribution License (http://creativecommons.org/licenses/by/2.0), which permits unrestricted use, distribution, and reproduction in any medium, provided the original work is properly cited.

\begin{abstract}
Exacerbations of chronic obstructive pulmonary disease (COPD) are important events in the natural history of this prevalent and devastating condition. This review provides a concise, state of the art summary on prevention and management of exacerbations. Considerable new data underpins evidence in support of many preventative interventions, pharmacological and nonpharmacological, that are now available. Challenges remain in developing new approaches, and delivering those that already exist to the right patient at the right time. Management of an exacerbation remains stepwise according to clinical severity, but there is now additional focus on addressing comorbidities and taking the opportunity at acute events to optimise preventative strategies for the future. Ultimately, exacerbations are heterogeneous events in a heterogeneous disease, and an individualised approach is paramount.
\end{abstract}

\section{Background}

Affecting $10 \%$ of the population over the age of 40 years [1], the burden of chronic obstructive pulmonary disease (COPD) has reached epidemic proportions. COPD is defined by the presence of poorly reversible airflow obstruction and an abnormal inflammatory response in the lung to noxious particles or gases [2]. Punctuating the decline in lung function are acute deteriorations in respiratory health, termed exacerbations. As discussed further below, exacerbations are important events in the natural history of COPD. This review provides a critical summary of present exacerbation therapies and aims to update the reader on recent developments in the treatment and prevention of exacerbations in COPD.

\section{The biology and importance of COPD exacerbations}

Exacerbations are key events in COPD, defined by the presence of worsening symptoms but also often associated with concurrent deteriorations in pulmonary function and increases in both local and systemic inflammation [3]. Exacerbations are caused by those insults that increase airway inflammation, principally episodes of bronchial infection, but also pollutants or stimuli that directly affect expiratory flow limitation [3].

Although it is generally true that exacerbations become more frequent as the severity of the underlying COPD increases [4], there are large differences in exacerbation 
incidence rates ('exacerbation frequency') between individual patients, and patients susceptible to more frequent exacerbations ('frequent exacerbators') appear to be a distinct phenotype susceptible to a more rapid decline in lung function [5,6], poorer quality of life [7] and increased mortality [8]. They are therefore a particularly important group to target for the exacerbation prevention strategies that are described below. There is emerging evidence to suggest that a proportion of patients with milder COPD may be susceptible to frequent exacerbations [9].

Exacerbations are very heterogeneous events ranging from no more than troublesome increases in respiratory symptoms to life-threatening episodes of respiratory failure. A typical community-treated exacerbation in a patient with moderately severe COPD has a short prodrome and a median symptom duration of 7 days, though some are considerably longer and a proportion of patients may never completely return to their pre-exacerbation baseline [10]. Exacerbations in more severe disease commonly require hospitalisation, and they are a much more common cause of emergency hospital admission than, for example, exacerbations of asthma [4]. Therefore, in addition to significant personal detriment to the patient, exacerbations of COPD demand a considerable portion of healthcare expenditure. Moreover, with an ageing population and relatively greater reductions in mortality from other prevalent diseases (notably cardiovascular disease) the burden of exacerbations continues to rise [1].

\section{Exacerbation diagnosis and treatment}

Exacerbations of COPD remain a clinical diagnosis of exclusion, and it is necessary to consider (and, where appropriate, rule out) other causes of increased breathlessness in patients with COPD presenting with symptom deteriorations [11]. Conditions mimicking exacerbations include pneumonia, pneumothorax, pulmonary embolus and cardiac failure. Diagnosis of exacerbation therefore requires appropriate clinical assessment and may need further investigation with, for example, chest radiography.

The principles of exacerbation therapy have not changed greatly since the widespread introduction in the 1990s of non-invasive ventilation in preference to doxapram for the treatment of hypercapnoea at exacerbation of COPD. Therapies at exacerbation may be divided into those thought to have a disease-modifying effect, and those aiming to support respiratory function until disease-modifying therapies have had sufficient time to act.

Exacerbation therapy is administered stepwise according to the clinical severity of presentation, and a general scheme is presented in Figure 1. It is important to note that disentangling the concept of exacerbation severity from the severity of the underlying COPD is almost impossible: a patient needing intubation and ventilation at exacerbation may have milder disease with a greater acute deterioration, or more severe underlying disease and a trivial insult.

The mainstay of therapy at exacerbation remains an increase in the dose and frequency of short-acting $\beta_{2}$ agonist and anticholinergic bronchodilators, and systemic corticosteroids for exacerbations not responding to this intervention alone. Antibiotics are generally added for exacerbations associated with a change in the characteristics of expectorated sputum. Oxygen with or without ventilatory support is necessary in the presence of respiratory failure, and often indicates the need for hospitalisation. Theophyllines are sometimes added in patients responding poorly to other therapies. Many national and international guidelines exist $[12,13]$.

Reviewing data from the original trials of these commonly prescribed therapies challenges our rationale for their use. Many exacerbations in the seminal study of antibiotics versus placebo improved in the placebo arm anyway [14], and the value of antibiotics has recently been further questioned in a systematic review in this journal [15]. There certainly appears to be no additional benefit from antibiotic courses lasting longer than 5 days compared to shorter regimes [16]. The major benefit of systemic corticosteroids is in increasing the rate of recovery of lung function, rather than more important endpoints such as mortality [17]. Indeed, there is evidence of relative corticosteroid resistance in COPD [18]. Whilst acknowledging the methodological limitations of such approaches, metaanalyses are available reporting summarised benefits at exacerbation for short-acting bronchodilators [19], systemic corticosteroids [20], antibiotics [21], theophyllines [22] and non-invasive ventilation (NIV) [23]. NIV has now all but replaced respiratory stimulants such as doxapram in the management of exacerbations with acute hypercapnoeic respiratory failure, and meta-analyses of NIV have documented a mortality benefit from such therapy over standard care [23]. However, NIV is not a replacement for endotracheal intubation and ventilation where this is necessary through severity or contraindication to NIV. Whilst the decision to intubate and ventilate a patient with COPD can be complex, outcomes in COPD are no worse than in patients with respiratory failure due to other causes [24] and any remaining therapeutic nihilism in this area should be challenged.

There is continuing interest in novel models of care including 'hospital at home'. Most data suggest that for selected patients such schemes are safe, and often preferred by patients [25], but that they are not necessarily more cost effective than traditional approaches.

Whilst pulmonary rehabilitation has an important role in preventing hospitalisations in COPD (discussed below), 


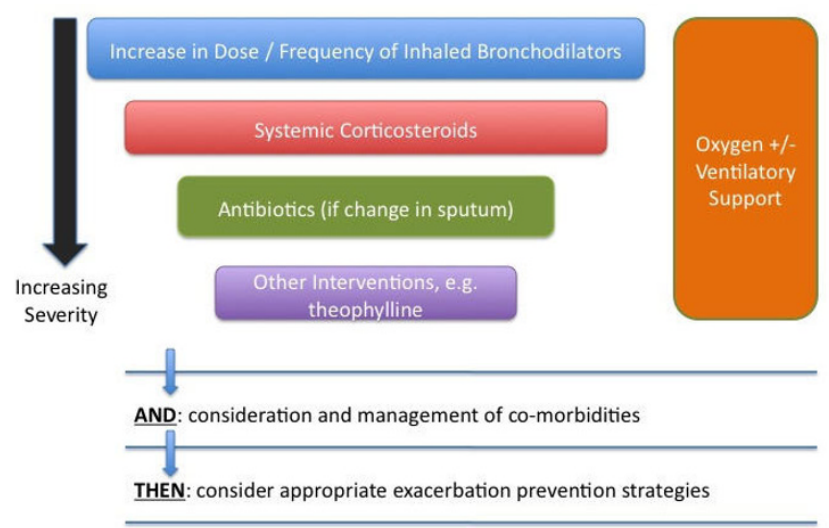

Figure I

General scheme for management of a chronic obstructive pulmonary disease (COPD) exacerba-

tion. Therapy is added stepwise according to the severity of the presentation. Mild exacerbations may respond to an increase in the dose and/or frequency of inhaled bronchodilators alone. Exacerbations not responding to this require systemic corticosteroids, with the addition of antibiotics if there has been a change in the character of expectorated sputum. Additional interventions such as theophylline may be required where the clinical response is still incomplete. Oxygen and/or ventilatory support may be necessary at any stage in the presence of new or established respiratory failure. Exacerbation management should also include an assessment and management of comorbidities, and the opportunity should be taken to optimise long-term therapies to reduce the risk of future exacerbations.

the concept of 'early rehabilitation' commenced during an acute exacerbation has not been definitively associated with improved outcomes. These results from a recent randomised controlled trial [26] contrast with those from an earlier meta-analysis of six smaller studies [27].

Intriguingly, further new data has suggested that treatment provided at a first exacerbation may affect the timing of second events. The addition of antibiotics to steroids, for example, has been associated with a reduced risk of subsequent recurrent exacerbation [28]. Indeed, it is now recognised that exacerbations are not random events, but rather cluster together in time such that in the period immediately following a first exacerbation there is increased risk of a second [29].

Future developments might be expected to include the validation of biomarkers to provide information on exacerbation aetiology and novel drugs, particularly antiviral agents and alternative anti-inflammatory agents to corticosteroids. Use of procalcitonin to inform on the likelihood of bacterial aetiology has been shown to safely reduce the use of antibiotics at exacerbation [30], but this concept is now complicated by the data referred to above suggesting that antibiotic treatment at one exacerbation may affect the timing of subsequent events [28]. It is also important to remark that the presence of bacteria in sputum at exacerbation does not imply that the organism is causative, and sputum bacterial colonisation is a frequent consequence of advancing COPD severity [31].

A final aspect of exacerbation therapy is data demonstrating that access to early treatment speeds exacerbation recovery [32] and this has led to many patients receiving 'emergency' courses of treatment to keep at home. However, data to specifically support self-management strategies (which requires self-diagnosis) are absent $[33,34]$.

\section{Exacerbation prevention}

In contrast to treatment of acute events, recent years have seen publication of landmark trials in COPD which inform on exacerbation prevention and we now have a wide range of options available, both pharmacological and non-pharmacological, to reduce exacerbation frequency. These are listed in Table 1, which also includes interventions known to reduce COPD hospitalisation (a closely related concept). Perhaps the greatest remaining challenge is to establish which patient will benefit from which combination of approaches, though there is still the need for novel interventions as current approaches are incompletely effective.

\section{Recent trials}

Although it has been known for some time that the three main classes of inhaled medication in COPD (corticosteroids, and long-acting anticholinergic and $\beta_{2}$ agonist bronchodilatiors) all reduce exacerbation frequency, there is compelling new data with regard to these drugs.

The TORCH trial (for 'TOwards a Revolution in COPD Health') [35] was published in 2007 and compared placebo, salmeterol, fluticasone and salmeterol-fluticasone (SFC) against a primary end point of all cause mortality. A total of 6,112 patients formed the efficacy population and the study duration was 3 years. Mortality data was carefully collected. The study supports the concept that combination treatment with SFC may reduce mortality,

Table I: Interventions known to reduce exacerbation frequency or frequency of hospitalisation in chronic obstructive pulmonary disease (COPD)

\begin{tabular}{ll}
\hline Pharmacological & Non-pharmacological \\
\hline Long-acting $\beta_{2}$ agonists & Pulmonary rehabilitation \\
Long-acting anticholinergics & Lung volume reduction surgery \\
Inhaled corticosteroids & Long-term oxygen therapy \\
Mucolytics & Domiciliary non-invasive ventilation \\
Erythromycin (macrolide) & Influenza vaccination
\end{tabular}


but at $P=0.052$ this just failed to achieve conventional statistical significance. Secondary outcomes included exacerbations and, supporting multiple earlier studies, there was evidence that all three active arms reduced exacerbations compared to placebo, with combination (SFC) treatment significantly better than either component alone. The annual rate of moderate and severe exacerbations in the placebo group was 1.13 per year, compared to 0.97 for salmeterol, 0.93 for fluticasone and 0.85 in patients receiving SFC. Like the subsequent trials described below, there was a significant preferential drop out rate from the placebo arm, complicating analysis, but which also represents a useful efficacy signal.

The Understanding Potential Long-term Impacts on Function with Tiotropium (UPLIFT) trial [36] was published in 2008 and compared the addition of tiotropium or placebo to current therapies with a primary end point of lung function decline. A total of 5,993 patients were randomised and the study duration was 4 years. The primary end point was negative, and once again the secondary endpoints included exacerbations. The addition of tiotropium resulted in a significant reduction in exacerbation frequency ( 0.73 per year tiotropium vs. 0.85 per year placebo, $P<0.001)$, which is important given that many patients were already taking combined inhaled corticosteroids with long-acting $\beta_{2}$ agonists.

The latter 'triple combination' approach is common in advanced COPD, and the only study to specifically examine this to date has been the Canadian OPTIMAL study [37]. This randomised 449 patients on tiotropium to additional placebo, salmeterol or SFC and had a 1-year duration. There was not a reduction in the primary endpoint of exacerbations in patients on tiotropium plus other therapy compared to tiotropium alone. These results are in keeping with a recent network meta-analysis published in this journal [38]. However, hospitalisations due to severe exacerbations were reduced in the group receiving tiotropium and SFC compared to tiotropium alone. Once again, patients on placebo were more likely to drop out. These data therefore question the 'triple combination' approach, at least with respect to the prevention of exacerbations and raise the concerning possibility of a ceiling effect for exacerbation preventative strategies.

The only head-to-head comparison of tiotropium versus SFC has been the Investigating New Standards for Prophylaxis In Reduction of Exacerbations (INSPIRE) study [39]. This randomised 1,323 patients to salmeterol-fluticasone or tiotropium over 2 years. Both treatments, as expected, reduced exacerbation frequency, and to a similar degree (to 1.28 per year for SFC and 1.32 per year for tiotropium, with a ratio of rates of 0.97 (95\% CI 0.84 to $1.12)$ ). Intriguingly however, the remaining exacerbations appeared to differ in phenotype depending on which drug the patient was taking: patients on SFC were more likely to need antibiotics at exacerbation whilst patients on tiotropium were more likely to require steroids. Which patients benefit most from which drug remains to be clarified. Perhaps a more important decision, which also remains to be adequately addressed, is which strategy to employ first in patients with milder disease.

\section{Other strategies}

Inhaled corticosteroids in combination with long-acting $\beta_{2}$ agonists, and long-acting anticholinergics are the principal pharmacological approaches to exacerbation reduction in COPD at present. Whilst combination corticosteroid and long-acting $\beta_{2}$ agonist therapy is recommended in both asthma and COPD, it is interesting to note that it is the inhaled corticosteroid that has had safety concerns in COPD, compared to the long-acting $\beta_{2}$ agonist component in asthma [40]. There is also evidence that mucolytics such as carbocisteine may be effective, especially in patients not taking inhaled corticosteroids [41]. Macrolide antibiotics have additional anti-inflammatory action and a recent single-centre, double-blind randomised trial of erythromycin $250 \mathrm{mg}$ twice a day over 1 year reported a $35 \%$ reduction in exacerbations [42]. Further confirmatory trials are ongoing. Other trials of prophylactic antibiotics are generally older [43], and there are ongoing concerns about the development of antibiotic resistance. Nevertheless, new strategies for the use of antibiotics are being studied such as intermittent or 'pulsed' therapy. As exacerbations are associated with additional inflammation, the effect of corticosteroids and macrolides in reducing exacerbations is perhaps to be expected. However, this would not explain the beneficial effect of 'pure bronchodilator' drugs such as tiotropium. It seems likely that a reduction in hyperinflation can also reduce exacerbation frequency (though tiotropium also has effects on mucus rheology).

New developments include ultra-long-acting (once daily) $\beta_{2}$ agonists and corticosteroids, and bronchodilators which possess both antimuscarinic and $\beta_{2}$ agonist activity. New classes of drugs are in development too, though none have yet been demonstrated to have an effect on exacerbation frequency.

Depression and anxiety are common in COPD [44], and likely also affect symptom perception and therefore exacerbation presentation. It is therefore important to detect and treat comorbid psychological conditions in COPD, though a specific effect on exacerbation reduction has not been documented.

Non-pharmacological approaches include influenza vaccination [45] and the recognised benefit in reducing hos- 
pitalisation of group, multiprofessional exercise and educational programmes (pulmonary rehabilitation) [46]. These programmes appear greater than the sum of their parts, and benefit from peer support. The finding that lung volume reduction surgery (LVRS; an approach in severe disease with heterogeneous distribution) reduced exacerbation frequency was perhaps unexpected [47] and this may also reflect the benefits of reducing hyperinflation. Criteria for long-term oxygen therapy (LTOT) are well established, and LTOT is one of the few interventions proven to have a mortality benefit in COPD [48,49]. Whilst a specific effect of oxygen on reducing exacerbations has not been demonstrated, there is evidence that underuse of LTOT where indicated results in increased hospital admissions [50]. A recent study has suggested that domiciliary NIV for COPD patients with hypercapnoeic respiratory failure may improve survival [51], but robust data in this field with regard to exacerbations also remain to be produced.

\section{Conclusion}

Exacerbations are important events in COPD. Management of the acute event remains dependent on inhaled short-acting bronchodilators, oral corticosteroids and antibiotics, with or without oxygen and ventilatory support. Comorbidities should be addressed. Given the importance of these events, effective care should also include deployment of strategies, both pharmacological and non-pharmacological, to reduce future exacerbations. Although new approaches are in development, a major current challenge is to understand which strategies to use in which patients at which stage of their disease. COPD exacerbations are heterogeneous events occurring in a heterogeneous disease and there is no 'one size fits all' approach to COPD exacerbation management and prevention.

\section{Abbreviations}

COPD: chronic obstructive pulmonary disease; LTOT: long-term oxygen therapy; LVRS: lung volume reduction surgery; NIV: non-invasive ventilation; SFC: salmeterolfluticasone.

\section{Competing interests}

JRH has received honoraria for attending advisory boards from Astra-Zeneca and Chiesi, and financial assistance to attend meetings from Astra-Zeneca, Boehringer-Ingelheim and GlaxoSmithKline. JAW has received honoraria for lectures or attending advisory boards from AstraZeneca, Bayer, Boehringer-Ingelheim, Chiesi, GlaxoSmithKline, Novartis and Pfizer and has current research grant support from Astra-Zeneca and GlaxoSmithKline.

\section{Authors' contributions}

The first draft was written by JRH; the manuscript was then revised and edited by JRH and JAW.

\section{References}

I. Mannino DM, Buist AS: Global burden of COPD: risk factors, prevalence, and future trends. Lancet 2007, 370:765-773.

2. Global Initiative for Chronic Obstructive Lung Disease: Global Strategy for the Diagnosis, Management and Prevention of Chronic Obstructive Lung Disease Updated 2007 [http:// www.goldcopd.com/Guidelineitem.asp?! | =2\&12=| \&intld=989]

3. Hurst JR, Wedzicha JA: The biology of a chronic obstructive pulmonary disease exacerbation. Clin Chest Med 2007, 28:525-536.

4. Donaldson GC, Wedzicha JA: COPD exacerbations. I: Epidemiology. Thorax 2006, 61:164-168.

5. Kanner RE, Anthonisen NR, Connett JE: Lower respiratory illnesses promote FEV, decline in current smokers but not exsmokers with mild chronic obstructive pulmonary disease. Am J Respir Crit Care Med 200I, 164:358-364.

6. Donaldson GC, Seemungal TAR, Bhowmik A, Wedzicha JA: Relationship between exacerbation frequency and lung function decline in chronic obstructive pulmonary disease. Thorax 2002, 57:847-852.

7. Seemungal TA, Donaldson GC, Paul EA, Bestall JC, Jeffries DJ, Wedzicha JA: Effect of exacerbation on quality of life in patients with chronic obstructive pulmonary disease. Am J Respir Crit Care Med 1998, I57:|4|8-|422.

8. Soler-Cataluña JJ, Martínez-García MA, Román Sánchez P, Salcedo E, Navarro M, Ochando R: Severe acute exacerbations and mortality in patients with chronic obstructive pulmonary disease. Thorax 2005, 60:925-931.

9. Anzueto A, Wedzicha JA, Hurst JR, Vestbo J, Yates J, Tal-Singer R, Miller D: Diagnosis of COPD exacerbations and their distribution based on GOLD severity stages. Am J Respir Crit Care Med 2009, I 79:A I 527.

10. Seemungal TA, Donaldson GC, Bhowmik A, Jeffries DJ, Wedzicha JA: Time course and recovery of exacerbations in patients with chronic obstructive pulmonary disease. Am J Respir Crit Care Med 2000, I6 I:1608-16I3.

II. Hurst JR, Wedzicha JA: What is (and what is not) an exacerbation of COPD: thoughts from the new GOLD guidelines. Tho$\operatorname{rax}$ 2007, 62:198-199.

12. National Institute for Clinical Excellence (NICE): Chronic obstructive pulmonary disease: national clinical guideline for management of chronic obstructive pulmonary disease in adults in primary and secondary care. Thorax 2004:59.

13. Celli BR, MacNee W, ATS/ERS Task Force: Standards for the diagnosis and treatment of patients with COPD: a summary of the ATS/ERS position paper. Eur Respir J 2004, 23:932-946.

14. Anthonisen NR, Manfreda J, Warren CP, Hershfield ES, Harding GK, Nelson NA: Antibiotic therapy in exacerbations of chronic obstructive pulmonary disease. Ann Intern Med 1987, 106:196-204.

15. Puhan MA, Vollenweider D, Steurer J, Bossuyt PM, Ter Riet G: Where is the supporting evidence for treating mild to moderate chronic obstructive pulmonary disease exacerbations with antibiotics? A systematic review. BMC Med 2008, 6:28.

16. El Moussaoui R, Roede BM, Speelman P, Bresser P, Prins JM, Bossuyt PM: Short-course antibiotic treatment in acute exacerbations of chronic bronchitis and COPD: a meta-analysis of double-blind studies. Thorax 2008, 63:4I5-422.

17. Davies L, Angus RM, Calverley PM: Oral corticosteroids in patients admitted to hospital with exacerbations of chronic obstructive pulmonary disease: a prospective randomised controlled trial. Lancet 1999, 354:456-460.

18. Barnes PJ, Adcock IM: Glucocorticoid resistance in inflammatory diseases. Lancet 2009, 373:1905-1917.

19. McCrory DC, Brown CD: Anticholinergic bronchodilators versus beta2-sympathomimetic agents for acute exacerbations of chronic obstructive pulmonary disease. Cochrane Database Syst Rev 2003, I:CD003900. 
20. Walters JA, Gibson PG, Wood-Baker R, Hannay M, Walters EH: Systemic corticosteroids for acute exacerbations of chronic obstructive pulmonary disease. Cochrane Database Syst Rev 2009, I:CD00I 288.

21. Ram FS, Rodriguez-Roisin R, Granados-Navarrete A, GarciaAymerich J, Barnes NC: Antibiotics for exacerbations of chronic obstructive pulmonary disease. Cochrane Database Syst Rev 2006, 2:CD004403.

22. Barr RG, Rowe BH, Camargo CA: Methylxanthines for exacerbations of chronic obstructive pulmonary disease: meta-analysis of randomised trials. BMJ 2003, 327:643.

23. Picot J, Lightowler J, Wedzicha JA: Non-invasive positive pressure ventilation for treatment of respiratory failure due to exacerbations of chronic obstructive pulmonary disease. Cochrane Database Syst Rev 2004, 3:CD004I04.

24. Nevins ML, Epstein SK: Predictors of outcome for patients with COPD requiring invasive mechanical ventilation. Chest 2001 I I 9: 1840-1849.

25. Ram FS, Wedzicha JA, Wright J, Greenstone M: Hospital at home for patients with acute exacerbations of chronic obstructive pulmonary disease: systematic review of evidence. BMJ 2004, 329:315.

26. Eaton T, Young P, Fergusson W, Moodie L, Zeng I, O'Kane F, Good $\mathrm{N}$, Rhodes L, Poole $\mathrm{P}$, Kolbe J: Does early pulmonary rehabilitation reduce acute health-care utilization in COPD patients admitted with an exacerbation? A randomized controlled study. Respirology 2009, I 4:230-238.

27. Puhan MA, Scharplatz M, Troosters T, Steurer J: Respiratory rehabilitation after acute exacerbation of COPD may reduce risk for readmission and mortality - a systematic review. Respir Res 2005, 6:54.

28. Roede BM, Bresser P, Bindels PJ, Kok A, Prins M, ter Riet G, Geskus RB, Herings RM, Prins JM: Antibiotic treatment is associated with reduced risk of a subsequent exacerbation in obstructive lung disease: an historical population based cohort study. Thorax 2008, 63:968-973.

29. Hurst JR, Donaldson GC, Quint JK, Goldring J], Baghai-Ravary R Wedzicha JA: Temporal clustering of exacerbations in chronic obstructive pulmonary disease. Am J Respir Crit Care Med 2009, I 79:369-374.

30. Stolz D, Christ-Crain M, Bingisser R, Leuppi J, Miedinger D, Müller C, Huber P, Müller B, Tamm M: Antibiotic treatment of exacerbations of COPD: a randomized, controlled trial comparing procalcitonin-guidance with standard therapy. Chest 2007, |31:9-19.

31. Sethi S, Murphy TF: Infection in the pathogenesis and course of chronic obstructive pulmonary disease. N Engl J Med 2008, 359:2355-2365.

32. Wilkinson TMA, Donaldson GC, Hurst JR, Seemungal TAR, Wedzicha JA: Early therapy improves outcomes of exacerbations of chronic obstructive pulmonary disease. Am J Respir Crit Care Med 2004, I 69: I 298-1303.

33. Turnock AC, Walters EH, Walters JA, Wood-Baker R: Action plans for chronic obstructive pulmonary disease. Cochrane Database Syst Rev 2005, 4:CD005074.

34. Effing T, Monninkhof EM, van der Valk PD, Zielhuis GA, Walters EH, van Herwaarden CL, van der Palen JJ, Zwerink M: Self-management education for patients with chronic obstructive pulmonary disease. Cochrane Database Syst Rev 2007, 4:CD002990.

35. Calverley PM, Anderson JA, Celli B, Ferguson GT, Jenkins C, Jones PW, Yates JC, Vestbo J, TORCH investigators: Salmeterol and fluticasone propionate and survival in chronic obstructive pulmonary disease. N Engl J Med 2007, 356:775-789.

36. Tashkin DP, Celli B, Senn S, Burkhart D, Kesten S, Menjoge S, Decramer M, UPLIFT Study Investigators: A 4-year trial of tiotropium in chronic obstructive pulmonary disease. $N$ Engl J Med 2008, 359:1543-1554

37. Aaron SD, Vandemheen KL, Fergusson D, Maltais F, Bourbeau J, Goldstein R, Balter M, O'Donnell D, Mclvor A, Sharma S, Bishop G, Anthony J, Cowie R, Field S, Hirsch A, Hernandez P, Rivington R, Road J, Hoffstein V, Hodder R, Marciniuk D, McCormack D, Fox G, Cox G, Prins HB, Ford G, Bleskie D, Doucette S, Mayers I, Chapman K, Zamel N, FitzGerald M, Canadian Thoracic Society/Canadian Respiratory Clinical Research Consortium: Tiotropium in combination with placebo, salmeterol, or fluticasone-salmeterol for treatment of chronic obstructive pulmonary disease: a randomized trial. Ann Intern Med 2007, I 46:545-555.

38. Puhan MA, Bachmann LM, Kleijnen J, Ter Riet G, Kessels AG: Inhaled drugs to reduce exacerbations in patients with chronic obstructive pulmonary disease: a network meta-analysis. BMC Med 2009, 7:2.

39. Wedzicha JA, Calverley PM, Seemungal TA, Hagan G, Ansari Z, Stockley RA, INSPIRE Investigators: The prevention of chronic obstructive pulmonary disease exacerbations by salmeterol/ fluticasone propionate or tiotropium bromide. Am J Respir Crit Care Med 2008, I77:19-26.

40. Fanta $\mathrm{CH}$ : Asthma. N Engl J Med 2009, 360:1002-1014.

4I. Zheng JP, Kang J, Huang SG, Chen P, Yao WZ, Yang L, Bai CX, Wang CZ, Wang C, Chen BY, Shi Y, Liu CT, Chen P, Li Q, Wang ZS, Huang Y], Luo ZY, Chen FP, Yuan JZ, Yuan BT, Qian HP, Zhi RC, Zhong NS: Effect of carbocisteine on acute exacerbation of chronic obstructive pulmonary disease (PEACE Study): a randomised placebo-controlled study. Lancet 2008 371:2013-2018.

42. Seemungal TA, Wilkinson TM, Hurst JR, Perera WR, Sapsford RJ, Wedzicha JA: Long-term erythromycin therapy is associated with decreased chronic obstructive pulmonary disease exacerbations. Am I Respir Crit Care Med 2008, I 78: I | 39- I | 47.

43. Black P, Staykova T, Chacko E, Ram FS, Poole P: Prophylactic antibiotic therapy for chronic bronchitis. Cochrane Database Syst Rev 2003, I:CD004I05.

44. Quint JK, Baghai-Ravary R, Donaldson GC, Wedzicha JA: Relationship between depression and exacerbations in COPD. Eur Respir J 2008, 32:53-60.

45. Poole PJ, Chacko E, Wood-Baker RW, Cates CJ: Influenza vaccine for patients with chronic obstructive pulmonary disease. Cochrane Database Syst Rev 2006, I:CD002733.

46. Casaburi R, ZuWallack R: Pulmonary rehabilitation for management of chronic obstructive pulmonary disease. $N$ Engl J Med 2009, 360:| 329-| 335.

47. Washko GR, Fan VS, Ramsey SD, Mohsenifar Z, Martinez F, Make B], Sciurba FC, Criner G], Minai O, Decamp MM, Reilly J), National Emphysema Treatment Trial Research Group: The effect of lung volume reduction surgery on chronic obstructive pulmonary disease exacerbations. Am J Respir Crit Care Med 2008, 177:164-169.

48. Nocturnal Oxygen Therapy Trial Group: Continuous or nocturnal oxygen therapy in hypoxemic chronic obstructive lung disease: a clinical trial. Ann Intern Med 1980, 93:39I-398.

49. Medical Research Council Working Party: Long term domiciliary oxygen therapy in chronic hypoxic cor pulmonale complicating chronic bronchitis and emphysema. Lancet I98I, I:68|-686.

50. Garcia-Aymerich J, Monsó E, Marrades RM, Escarrabill J, Félez MA Sunyer J, Antó JM, EFRAM Investigators: Risk factors for hospitalization for a chronic obstructive pulmonary disease exacerbation. EFRAM study. Am J Respir Crit Care Med 200I, I 64: 1002-1007.

5I. McEvoy RD, Pierce RJ, Hillman D, Esterman A, Ellis EE, Catcheside PG, O'Donoghue FJ, Barnes DJ, Grunstein RR, Australian trial of noninvasive Ventilation in Chronic Airflow Limitation (AVCAL) Study Group: Nocturnal non-invasive nasal ventilation in stable hypercapnic COPD: a randomised controlled trial. Thorax 2009, 64:56I-566.

\section{Pre-publication history}

The pre-publication history for this paper can be accessed here:

http://www.biomedcentral.com/1741-7015/7/40/prepub 